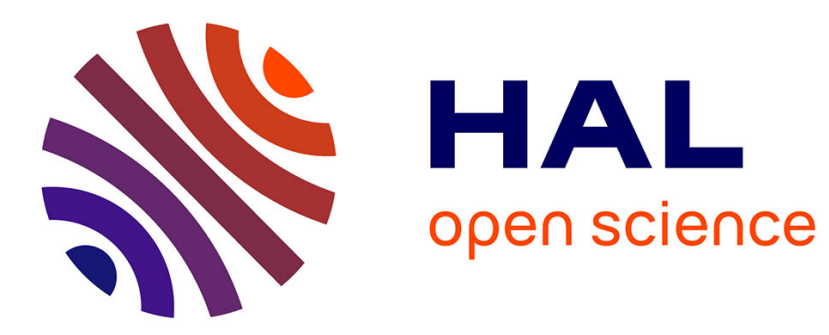

\title{
Is competition or collusion in the product market relevant for labour market?
}

Fabian Berges, Stéphane Caprice

\section{To cite this version:}

Fabian Berges, Stéphane Caprice. Is competition or collusion in the product market relevant for labour market?. Recherches Economiques de Louvain - Louvain economic review, 2008, 74 (3), pp.273-298. 10.3917/rel.743.0273 . hal-02655208

\section{HAL Id: hal-02655208 \\ https://hal.inrae.fr/hal-02655208}

Submitted on 29 May 2020

HAL is a multi-disciplinary open access archive for the deposit and dissemination of scientific research documents, whether they are published or not. The documents may come from teaching and research institutions in France or abroad, or from public or private research centers.
L'archive ouverte pluridisciplinaire HAL, est destinée au dépôt et à la diffusion de documents scientifiques de niveau recherche, publiés ou non, émanant des établissements d'enseignement et de recherche français ou étrangers, des laboratoires publics ou privés. 


\title{
Is competition or collusion in the product market relevant for labour markets? ${ }^{*}$
}

\author{
Fabian Bergès $^{* *}$ and Stéphane Caprice ${ }^{* * *}$
}

\section{Introduction}

This article analyses the interaction between oligopsonistic competition on the labour market and oligopolistic price-setting on the product market.

Focusing on the labour market, Manning (2003) presents a model that combines the job differentiation and search aspects. Hamilton et al. (2000) study imperfect competition in the labour market when both workers and firms are heterogeneous. These authors consider an industry with firms producing a given homogeneous good that is sold on a competitive market. ${ }^{1}$ However, analysis of oligopsonistic competition in the labour market typically do not include explicit models of the product market or the oligopolistic strategies of firms. Hence, such analysis are unable to investigate the interactions between products and the structure and behaviour of the labour market.

By contrast, if wages are bargained collectively, it is possible to construct plausible and robust models to study the connections between the labour and product markets. Davidson (1988) developed a model of wage determination in unionized oligopolistic industries and used it to compare the outcome of collective bargaining under different negotiation structures. Horn and Wolinski (1988) analysed a duopoly situation in which firms acquire inputs (labour). They combined a bargaining model with a duopoly model to examine the effect of the industry's structure on input prices (wages) and profits, the demand relations among the final products, as well as the nature of bargaining between unions and firms. ${ }^{2}$ However, since union

\footnotetext{
We are grateful for remarks from EARIE (2003), Labour Seminar at the University of Warwick, Applied Economics Seminar at Inra-Toulouse (2003) and EALE (2004) participants. This article was finalized while Stéphane Caprice was a visiting fellow at the Warwick University during the year 2004-2005.

** Toulouse School of Economics (GREMAQ, INRA, DEI); UMR 1291, 21 Allée de Brienne, F-31000 Toulouse.

** Toulouse School of Economics (GREMAQ, INRA); UMR 1291, 21 Allée de Brienne, F-31000 Toulouse; Correspondence to: caprice@ toulouse.inra.fr.

1 See also an interesting review on imperfect competition in labour markets, given by Bhaskar et al. (2002).

2 A recent review can be found in Naylor (2003).
} 
bargaining does not provide a full explanation of the wage setting process, oligopsonistic competition in the labour market should also be considered. Indeed, according to the quantitative analyses of Cahuc et al. (2006) and Beffy et al. (2006), between-firm competition for labour services plays a prominent role in the wage setting process.

In this context, our article can be regarded as an attempt to model the interaction between product and labour markets in oligopolistic industries, a structure widely neglected in the labour literature. ${ }^{3}$ We consider a model of wage-setting in the labour market and price-setting in the product market.

In our study, we address a number of questions, including whether an increase in product market power and profitability can lead to increased wages. This question is relevant since, even in the non-union sector, evidence is found of monopoly rents being shared by workers in the form of higher wages (Stewart, 1990; Blanchflower et al., 1996). We also investigate how wage-setting in the labour market can be influenced by demand relations among the products or behaviour of firms in the product market. As pointed out by Nickell (1999), a major problem with such an analysis is to take into account of the endogeneity of the level of employment, and perhaps more importantly, any changes in the quality or skill level of the labour force. For instance, any fluctuation in the workers' productivity or skill level will typically induce parallel fluctuations in both wages and quasirents. Product market characteristics do not only affect wage determination, but also the employment as well as the skill level of the labour force and the firm's productivity performance.

We take into account a qualified labour market where workers are heterogeneous with respect to their specialisation and an unqualified labour market where there is an infinite supply of labour. We consider a two-stage game with two firms. Firstly, firms compete on the qualified labour market. Productivity performance is related to the number of qualified workers, that is, it increases with the number of qualified workers. Secondly, firms set prices in the product market and then produce outputs. Qualified workers and unqualified workers are employed for production. The numbers of unqualified and qualified workers hired by the firms are thus endogenous. At this stage, we should bear in mind that we are addressing the following question: what happens to wages, employment and productivity if there is a change in market power on the product market? We thus consider two contrasting (or extreme) cases, in which firms either compete or collude on the product market. This is a partial equilibrium issue, where unions do not influence wage determination. We model the product market power (leading to higher rents) by using a market behaviour approach.

3 See Wauthy and Zenou (2000) for a notable exception. 
We find that, under collusion, firms hire more qualified workers. Wages in the qualified labour market are higher to attract workers. This result is in accord with some studies showing that collusion on price increases the firms' incentives to make cost-reducing or quality enhancing investments when they choose strategic variables other than production and prices, like investment in capacity or R\&D spending. ${ }^{4}$ Collusion in the product market intensifies competition on other strategic decisions, such as the wages of qualified workers. In our study, the productivity increases along with the number of qualified workers employed.

However, we also find that total employment (unqualified plus qualified workers) decreases with collusion. We perform a numerical analysis to compare the wage bill in a collusive and in a non-collusive framework. Depending on product market parameters, the total wage bill is lower in a collusive setting when the final demand for goods and degree of substitution between goods are low. Thus, in a product market collusion setting, qualified workers earn more, but less rents may be distributed to all workers. Furthermore, the wage gap between unqualified and qualified workers increases.

Some of the topics analysed here have also been explored in a number of recent papers. Symeonidis (2005) examined the effects of collusion in the product market when there is bargaining between downstream firms and upstream agents (firms and unions) over the price of an input (such as labour), while Lommerud et al. (2005 and 2006) investigated the profitability of downstream mergers when each downstream firm is faced with an input price unilaterally set by an upstream supplier. In our model, a downstream merger may correspond to the case of collusion by joint profit maximisation. In contrast to our findings, these authors (op. cit.) propose that joint profit maximisation in the product market will lead to lower input prices (wages). However, our approach is very different. Most importantly, we examine competition in the labour market, whereas previous authors assumed bargaining (Symeonidis, 2005) or wages that were unilaterally set by unions (Lommerud et al., 2005 and 2006). We also take into account the distribution of skilled and unskilled workers, which results in productivity changes for firms.

Some other recent studies focus on issues that are complementary to the ones analysed here. For example, technology spillovers are endogenous through labour mobility, and certain authors have studied the links between product markets and technology spillovers. Fosfuri et al. (2001) analysed technology spillovers due to worker mobility from multinationals to local firms. Gersbach and Schmutzler (2003) investigated how endogenous spillovers through R\&D-employees' mobility can influence incentives to invest

4 For example, see Fershtman and Gandal (1994). Along the same lines, Horn et al. (1994) show that contrary to popular belief - there may be a negative relation between the competitiveness of the product market and effort incentives in R \& D. 
in cost-reducing innovations. Fosfuri and Rønde (2004) and Combes and Duranton (2006) studied the functioning of industrial clusters in cases where technology spillovers arise through labour mobility. Our analysis is complementary to previous studies, which consider only the diffusion of knowledge as endogenous, viewing the initial recruitment of strategic workers as an exogenous investment. By contrast, although our study does not examine the diffusion of knowledge, we consider that only the generation of knowledge is endogenous due to the recruitment of strategic workers.

Lastly, our model contributes to the extensive literature on strategic technological choices. Hiring qualified workers is a form of strategic investment that allows a firm to lower its marginal cost before competition takes place on the product market (Vives, 1989; Mills and Smith, 1996).

This article has the following structure. The first section describes the model. The second section presents equilibria for the two "extreme" situations, in which i) firms compete on both prices and wages and ii) firms collude on product market prices, but compete on the labour market. Note that the strategic labour market is made up of qualified workers. The third section compares the two situations in terms of wages, productivity and total employment, while also presenting a numerical analysis of the wage bill. The last section is a conclusion.

\section{The model}

We consider a partial equilibrium model with two differentiated goods, each one produced by a different firm $(i=1,2)$. We assume a dual labour market. There is an infinite supply of unqualified labour at a wage $w$ and the two firms compete for hiring qualified workers. The firms play a two-stage game (competition on qualified workers' wages and price setting). Although qualified workers are not needed by the firms to be able to produce later on, productivity at the second stage results from the number of qualified workers hired at the first stage.

\subsection{The two-stage game}

In the first stage, firms set the wages of their qualified workers and then hire them. The wage $w$ of unqualified labour is normalized to unity, without loss of generality. The wage proposed by firm $i$ to qualified workers is denoted by $1+w_{i}$, where $w_{i}$ is the gross premium over the market wage for unqualified labour taken as equal to 1 . In the following, we refer to the premium chosen by the firms as the strategic wage since the wage for unqualified labour is non-strategic. We assume $c_{i}$ is the constant labour requirement per 
unit of output for firm $i$. Hiring qualified workers reduces this firm's unit labour requirement; $c_{i}$ decreases as a linear function of the number of qualified workers $l_{i}$ according to:

$$
c_{i}=\left\{\begin{array}{l}
1-l_{i} \text { if } l_{1} \leq 1 \\
0 \text { otherwise }
\end{array}\right.
$$

At the end of this first stage, firms are ready to operate and production facilities are set up. In the second stage, price setting takes place $\left(p_{i}\right.$ and $\left.p_{j}\right)$ and firms produce their output. Qualified workers and unqualified workers are employed for production during this period. ${ }^{5}$ Firms hire unqualified labour, $s_{i}$, to produce the corresponding quantity $q_{i}\left(p_{i}, p_{j}\right)$, such that:

$$
l_{i}+s_{i}=c_{i} q_{i}\left(p_{i}, p_{j}\right) \text { if } l_{i}<c_{i} q_{i}\left(p_{i}, p_{j}\right)
$$

There is a possibility for the firm to hire 'too many' qualified workers, resulting in a lack of unqualified recruitment. This strategy is ruled out in our model since the symmetric equilibrium is defined for a positive value of $s_{i}{ }^{6}$

Wages are then paid for qualified and unqualified workers. The profit of firm $i$ is the sum of its revenues on the product market minus the wages paid, that is: $p_{i} q_{i}\left(p_{i}, p_{j}\right)-s_{i}-\left(1+w_{i}\right) l_{i}$. Using (1) and (2), the profit of firm $i$ can be rewritten as:

$$
\pi_{i} \equiv\left(p_{i}-c_{i}\right) q_{i}\left(p_{i}, p_{j}\right)-w_{i}\left(1-c_{i}\right)
$$

The structure of the game and its timing are summarised in Figure 1.

Stage 1:

Strategic Wage Competition

-Setting of qualified workers' wages

- Hiring of qualified workers

- Setting-up of firms' productivity
Stage 2:

Price Competition

Time

- Setting of prices

- Hiring of non qualified workers

- Production takes place

- Wages are paid (qualified and non qualified workers)

Figure 1: Timing of the game

5 As suggested by one anonymous referee, we could instead assume that qualified workers do not contribute directly to the production, but operate for instance as "team supervisors" or "foremen". The unit labour requirement still decreases, but only unqualified workers participate in the production process. This would not change the nature of our results.

6 We thank the two anonymous referees for pointing out this problem. We checked that the interior solution in prices is a global maximum at the symmetric equilibrium such that $s_{i}>0$ (a proof can be provided upon request). The condition $s_{i}>0$ is transposed into equations (C3) and (C3'), which are available in Annexes $B$ and $C$. 
The timing is consistent in the sense that hiring qualified workers is a way for firms to invest firstly in production facilities: qualified workers contribute to the internal knowledge of the firm and thus its productivity. Hence, it is appropriate that competition for qualified workers occurs in stage 1 , whereas price setting and production takes place in stage 2 (as described in Combes and Duranton, 2006). Furthermore, hiring qualified workers is often less flexible than hiring unqualified workers. The problem of matching between qualified workers and the activities of firm $i$ can be seen as much more complex: qualified workers may require some training cost to work in firm $i$.

\subsection{The strategic (qualified) labour market}

We assume a qualified labour market where there is a continuum of workers with the same level of general human capital, but with heterogeneous skills. Workers are heterogeneous in the type of work they are best suited for, but there is no kind of ranking in these types of work. Workers' skill types are denoted by $x$ and, for simplicity, the common level of general human capital is ignored. Our modelling of the qualified labour market is closely related to that due to Hamilton et al. (2000). ${ }^{7}$

The relevant characteristics of a given (qualified) worker with respect to firms are summarised by his or her skill. Each firm has a specific technology such that workers can produce output only when they fully match the firm's skill requirement. Since workers are heterogeneous, they have different matches with the firm's job offer. Thus, if firm $i$ hires a worker whose skill differs from $x_{i}$, the worker will need to be trained. The cost of training to meet the firm's skill requirement is a function of the difference between the worker's skill $x$ and the skill requirement $x_{i}$. The more distant the skill of a worker from the firm's skill requirement, the larger the training cost. More precisely, the training cost is given by a linear function $t\left|x-x_{i}\right|$ of the difference between the worker's skill $x$ and the firm's skill requirement $x_{i}$, where $t>0$ is a parameter inversely related to the efficiency of the training process. Besides, $t$ could also be related to the degree of competition between firms on the qualified labour market. In the limit case where $t \rightarrow 0$, the training process has no cost; this limit case is equivalent to perfect Bertrand competition on wages. For simplicity, we assume that qualified workers' skills are uniformly distributed along a segment $\left[-\frac{1}{h}, \frac{1}{h}\right]$. The constant uniform density is $h$, which expresses the thickness of the market. ${ }^{8}$

7 For a model in which workers are heterogeneous with respect to general human capital, see Sattinger (1993).

8 In our modelling, the segment length should be at least 2 to reflect a labour market that is not fully covered. To be precise, a qualified labour market size equal to 2 implies $x \in\left[-\frac{1}{h}, \frac{1}{h}\right]$, since the uniform density is $h$. A direct consequence is that the number of qualified workers can vary. 
Note that the wage proposed by firm $i$ to qualified workers is $1+w_{i}$, so an individual with characteristic $x$ and taking a job in firm $i$ has a net utility that is given by:

$$
w_{i}-t\left|x-x_{i}\right|
$$

Each firm requires a specific specialization profile and we assume that these profiles are located around 0, the centre-line of specialization. For the sake of simplification, the skill requirements are taken as $x_{1}=-\frac{1}{2}$ and $x_{2}=\frac{1}{2}$.

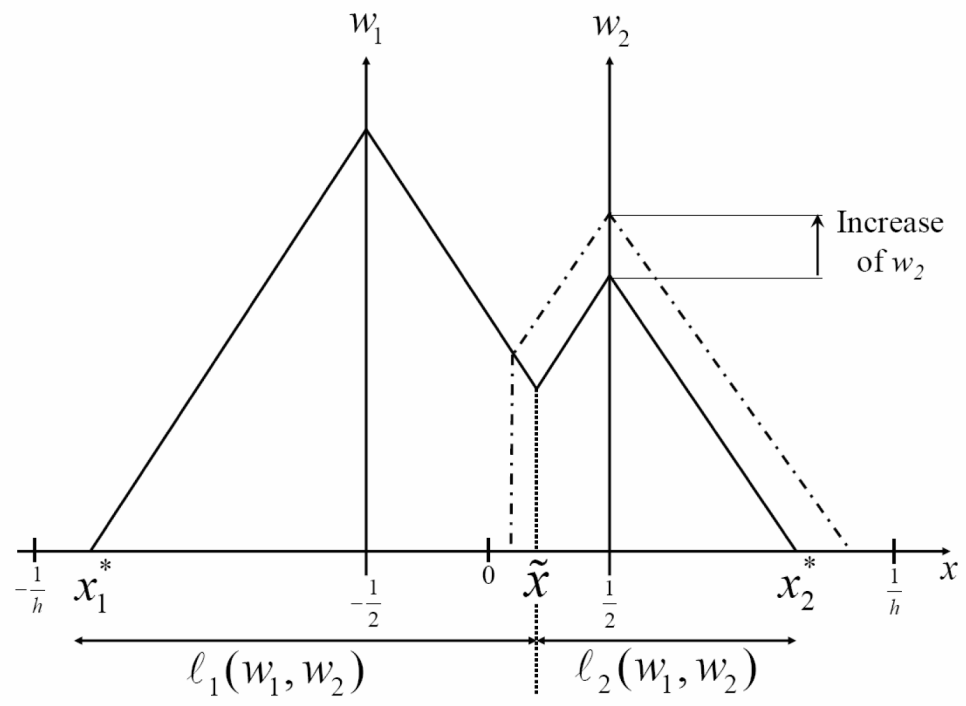

Figure 2: The qualified market and the effects of increasing $w_{2}$

For interior strategic wage solutions, given that firm $i$ proposes $w_{i}$ and its rival firm $w_{j}$, the number of qualified workers accepting the job is given by (see Annex A for details):

$$
\begin{gathered}
l_{i}\left(w_{i}, w_{j}\right)=\frac{\left(3 w_{i}-w_{j}+t\right)}{2 t} h \text { with } i \neq j=\{1,2\}, \\
t<w_{i}+w_{j} \text { and } w_{i}<t\left(\frac{1}{h}-\frac{1}{2}\right) .
\end{gathered}
$$

For the symmetric equilibrium in wages, where $w_{1}=w_{2}=w$, we can note that the conditions in (5) amount to:

$$
\frac{t}{2}<w<t\left(\frac{1}{h}-\frac{1}{2}\right) \text { which is relevant if } h<1 .
$$


An increase in the strategic wage offered by firm $i$ has two different effects. Firstly, this pay rise allows firm $i$ to increase its market share on the qualified labour market by convincing workers who were employed by firm $j$ to obtain a job in firm $i$. This is illustrated in Figure 2, which shows that $\tilde{x}$ is shifted to the left (for a given rise of $w_{2}$ ). Secondly, an increase in $w_{i}$ also persuades some qualified workers who were not employed in the strategic labour market to take a qualified job in firm $i$. This is because their net utility then becomes positive owing to the higher $w_{i}{ }^{9}$. Thus, the total number of qualified workers employed (both in firms $i$ and $j$ ) increases because of this latter effect.

\subsection{The product market}

At stage 2, firms set prices on the product market and the goods produced are considered as imperfect substitutes by consumers. Inverse demand functions are classically given by:

$$
p_{i}=\alpha-q_{i}-\beta q_{j} \text { and } p_{j}=\alpha-q_{j}-\beta q_{i}
$$

where $q_{i}$ is the quantity consumed of the good produced by firm $i$, with $\alpha>1$ and $0 \leq \beta<1$. Rearranging terms leads to the following linear demand functions:

$$
q_{i}\left(p_{i}, p_{j}\right)=\frac{\alpha}{1+\beta}+\frac{\beta}{1-\beta^{2}} p_{j}-\frac{1}{1-\beta^{2}} p_{i} \text { with } i \neq j=\{1,2\} .
$$

The parameter $\alpha$ can be interpreted as reflecting the market size, whereas $\beta$ is an inverse-index for the degree of differentiation between the two goods. In the particular case where $\beta=0$, firms are in a monopoly position in their markets, whereas the limit case $\beta \rightarrow 1$ is equivalent to Bertrand competition with homogeneous goods.

\section{Two-Product Market Equilibria}

Product market power (leading to higher rents) is captured by considering two extreme cases: firms competing on the product market, and, on the contrary, firms colluding on the product market. The first case is considered here as the benchmark situation.

9 Such an effect is absent when considering a fully covered labour market with inelastic labour supply. Indeed, any increase in strategic wage results in an increase of the firm's market share. 


\subsection{The benchmark case: competition on the product market}

In the following, we derive the equilibrium in prices and wages when firms compete firstly in the strategic labour market and then on the product market.

The game consists of two stages:

- In the first stage, firms offer bonus wages of $w_{1}$ and $w_{2}$ to qualified workers. Wage offers are assumed to be public.

- In the second stage, firms compete in prices on the product market.

To find the sub-game perfect Nash-equilibrium, the game is solved by backward induction. The program of firm $i$ according to (3) is given by:

$$
\begin{gathered}
\max _{P_{i}}\left(p_{i}-c_{i}\right) q_{i}\left(p_{i}, p_{j}\right)-w_{i}\left(1-c_{i}\right) \\
\mathrm{s} / \mathrm{t} \quad c_{i}=1-l_{i} \text { and } q_{i}\left(p_{i}, p_{j}\right)=\frac{\alpha}{1+\beta}+\frac{\beta}{1-\beta^{2}} p_{j}-\frac{1}{1-\beta^{2}} p_{i} .
\end{gathered}
$$

The first-order conditions on price give the following equilibrium in terms of price and quantity for firm $i$ :

$$
\begin{gathered}
p_{i}\left(c_{i}, c_{j}\right)=\frac{\alpha(1-\beta)}{2-\beta}+\frac{2 c_{i}+\beta c_{j}}{(2+\beta)(2-\beta)}, \\
q_{i}\left(c_{i}, c_{j}\right)=\frac{\alpha}{(2-\beta)(1+\beta)}+\frac{\beta c_{j}-\left(2-\beta^{2}\right) c_{i}}{(2+\beta)(2-\beta)(1+\beta)(1-\beta)} .
\end{gathered}
$$

The profit of firm $i$ in terms of production costs is therefore:

$$
\pi_{i}\left(c_{i}, c_{j}\right)=\frac{\left[\alpha(2+\beta)(1-\beta)+\beta c_{j}-\left(2-\beta^{2}\right) c_{i}\right]^{2}}{(2-\beta)^{2}(2+\beta)^{2}(1+\beta)(1-\beta)}-w_{i}\left(1-c_{i}\right) .
$$

At this stage of the game, $c_{i}$ is considered as fixed because the wage $w_{i}$ was already set in the previous stage. We now turn to the Nash-equilibrium in strategic wages. Since $c_{i}$ depends on $w_{i}$ and $w_{j}$, the expression of firm $i$ 's profit relative to wages is given by:

$$
\pi_{i}\left(w_{i}, w_{j}\right) \equiv \pi_{1}\left(p_{i}\left(c_{i}\left(w_{i}, w_{j}\right), c_{j}\left(w_{i}, w_{j}\right)\right), p_{j}\left(c_{i}\left(w_{i}, w_{j}\right), c_{j}\left(w_{i}, w_{j}\right)\right), c_{i}\left(w_{i}, w_{j}\right), w_{i}\right) .
$$

The first-order condition with respect to $w_{i}$ is written as:

$$
\underbrace{\frac{\partial \pi_{i}}{\partial p_{i}}}_{=0}[.]+\frac{\partial \pi_{i}}{\partial p_{j}}\left[\frac{\partial p_{j}}{\partial c_{i}} \frac{\partial c_{i}}{\partial w_{i}}+\frac{\partial p_{j}}{\partial c_{j}} \frac{\partial c_{j}}{\partial w_{i}}\right]+\frac{\partial \pi_{i}}{\partial c_{i}} \frac{\partial c_{i}}{\partial w_{i}}+\frac{\partial \pi_{i}}{\partial w_{i}}=0 .
$$

Considering only symmetric Nash-equilibria, we can then determine the equilibrium strategic wages. 
Proposition 1: Assuming that firms compete on the product market, the interior equilibrium in strategic wages is given by:

$$
w^{*}=\frac{t^{2}-A\left(\alpha-1+\frac{h}{2}\right) t}{h A-5 t} \text { where } A=\frac{12+2 \beta-6 \beta^{2}}{(1+\beta)(2+\beta)(2-\beta)^{2}}>0 \text {. }
$$

The comparative statics results are summarised as follows:

$$
\frac{d w^{*}}{d \alpha}>0, \frac{d w^{*}}{d \beta}<0, \frac{d w^{*}}{d h}>0 \text { and } \frac{d w^{*}}{d t}<0 .
$$

Proof. See Annex B. Conditions for interior solutions and existence are also provided.

The variations in equilibrium wage appear quite intuitive in relation to the model parameters. When the market size increases, each firm shows a rise in profitability and hires more on the qualified labour market. This competition for qualified workers makes the equilibrium wage increase. When goods on the product market become increasingly substitutes, equilibrium prices decrease so the firm has to cut the wage bill. This leads to hiring less qualified workers who are expensive, and thus the equilibrium wage decreases. These results fit with the common view that wage determination is positively influenced by the employers' ability to pay. We find that rent-sharing income increases with market size, but decreases with the degree of substitutability between products. This occurs independently of union bargaining, since we have no union in this model.

For any increase in the size of the qualified labour market, each firm benefits equally from the increased numbers of qualified workers hired and thus competition on the labour market leads to a rise in the strategic wage. This seems to be counter-intuitive in the sense that an increase in the number of workers usually implies lower wages. It is not the case in our model because a larger qualified labour market increases the marginal supply of qualified workers, for a given increase in the wage offered. Finally, an increase in the matching cost of employees turns this labour market to be less competitive. Each firm exerts its market power on qualified workers and therefore lowers the strategic wage offered.

\subsection{Collusive agreement on the product market}

The difference with the benchmark competing situation only arises in the second stage of the game when firms collude in prices. However, as previously described for the first stage, firms continue to compete on the qualified labour market. Collusion only takes place on the product market.

The price equilibrium in the second stage can therefore be obtained from the joint profit maximisation program: 


$$
\begin{gathered}
\max _{\left\{p_{\mathrm{v}}, p_{2}\right\}} \sum_{i=1}^{2}\left[\left(p_{i}-c_{i}\right) q_{i}\left(p_{i}, p_{j}\right)-w_{i}\left(1-c_{i}\right)\right] \\
\mathrm{s} / \mathrm{t} \quad c_{i}=1-l_{i} \text { and } q_{i}\left(p_{i}, p_{j}\right)=\frac{\alpha}{1+\beta}+\frac{\beta}{1-\beta^{2}} p_{j}-\frac{1}{1-\beta^{2}} p_{i} .
\end{gathered}
$$

The first-order condition computations give the following collusive equilibrium in prices and quantities:

$$
\begin{gathered}
\tilde{p}_{i}\left(c_{i}\right)=\frac{1}{2}\left(\alpha+c_{i}\right), \\
\tilde{q}_{i}\left(c_{i}, c_{j}\right)=\frac{\alpha}{2(1+\beta)}+\frac{\beta c_{j}-c_{i}}{2(1+\beta)(1-\beta)} .
\end{gathered}
$$

The profit of firm $i$, expressed only in terms of cost parameter, can be rewritten as:

$$
\tilde{\pi}_{i}\left(c_{i}, c_{j}\right)=\frac{\left(\alpha-c_{i}\right)^{2}-\beta\left(\alpha-c_{i}\right)\left(\alpha-c_{j}\right)}{4(1+\beta)(1-\beta)}-w_{i}\left(1-c_{i}\right) .
$$

The profit of firm $i$ in the collusion framework expressed with respect to $w_{i}$ and $w_{j}$ can be written as:

$$
\pi_{\mathrm{i}}\left(\tilde{p}_{i}\left(c_{i}\left(w_{i}, w_{j}\right), c_{j}\left(w_{i}, w_{j}\right)\right), \tilde{p}_{j}\left(c_{i}\left(w_{i}, w_{j}\right), c_{j}\left(w_{i}, w_{j}\right)\right), c_{i}\left(w_{i}, w_{j}\right), w_{i}\right),
$$

where $\tilde{p}_{i}$ and $\tilde{p}_{j}$ are the price solutions of the joint profit maximisation on the product market.

When there is collusion on the product market, the first-order condition determining the wage equilibrium of firm $i$ can be written as:

$$
\frac{\partial \pi_{i}}{\partial p_{i}}\left[\frac{\partial \tilde{p}_{i}}{\partial c_{i}} \frac{\partial c_{i}}{\partial w_{i}}+\frac{\partial \tilde{p}_{i}}{\partial c_{j}} \frac{\partial c_{j}}{\partial w_{i}}\right]+\frac{\partial \pi_{i}}{\partial p_{j}}\left[\frac{\partial \tilde{p}_{j}}{\partial c_{i}} \frac{\partial c_{i}}{\partial w_{i}}+\frac{\partial \tilde{p}_{j}}{\partial c_{j}} \frac{\partial c_{j}}{\partial w_{i}}\right]+\frac{\partial \pi_{i}}{\partial c_{i}} \frac{\partial c_{i}}{\partial w_{i}}+\frac{\partial \pi_{i}}{\partial w_{i}}=0
$$

Considering only symmetric Nash-equilibria on the qualified labour market, we can then determine the equilibrium strategic wages.

Proposition 2: Assuming that firms collude on the product market, the interior equilibrium in strategic wage is given by:

$$
w^{* *}=\frac{t^{2}-C\left(\alpha-1+\frac{h}{2}\right) t}{h C-5 t} \text { where } C=\frac{3-\beta}{2(1-\beta)(1+\beta)}>0 .
$$

Comparative statics results are summarised as follows:

$$
\frac{d w^{* *}}{d \alpha}>0, \frac{d w^{* *}}{d \beta} \gtrless 0, \frac{d w^{* *}}{d h}>0 \text { and } \frac{d w^{* *}}{d t}<0 .
$$


Proof. See Annex C. Conditions for interior solutions and existence are also provided.

The effects contributing to the variation of the equilibrium wage with respect to parameters $\alpha, h$ and $t$ are the same as in the previous section. The sign of $\frac{d w^{* *}}{d \beta}$ is not constant. ${ }^{10}$

According to the firms' behaviour in the product market, we compare both framework outcomes to see whether collusive agreement on the product market is relevant or not.

\section{Is product market competition relevant for labour market outcomes?}

Following the review carried out by Nickell (1999), the basic relationship between the labour and the product markets relies on sharing of the monopoly rents. However, to share the rents, we require a rule or an institution, and models including the effect of unions yield a positive relationship between market power and wages. An increase in market power implies more monopoly rent to share via union negotiations on wages.

There is no union involved in our model, and wage levels arise from the imperfect competition between firms in the labour market. Considering collusion on the product market, the result is a rise in prices and more rents to share. Nevertheless, the effect of collusion may be ambiguous, since this means that each firm produces less and therefore hires fewer numbers of workers. An intuitive conclusion would be that collusion leads to lower wages in the labour market. However, since collusion gives more rents to share, firms have a larger return on investment when they employ more qualified workers. ${ }^{11}$ Hence, collusion may lead to more competition on the qualified labour market.

We successively compare the wage as well as the level of employment and productivity performance. A numerical analysis is performed to compare the wage bill.

10 The fact that $\frac{d w^{* *}}{d \beta} \neq 0$ needs some explanation. Usually, collusion on the product market should completely internalise the substitution parameter between products because firms act as if they were a downstream multiproduct monopoly. In our model, total demand $\left(q_{1}+q_{2}\right)$ depends on $\beta$ and this creates the well known bias of $\beta$ operating on market size. See Irmen (1997) for a documented criticism on this kind of linear demand function. Therefore, the sign of this derivative does not depend on any relevant economic explanation.

11 Such an effect arises because of the intrinsic link between productivity and the number of qualified workers present in the firm. 


\subsection{The effect of collusion on wage, productivity and total employment}

Employing qualified workers implies an efficiency effect for the firm since it helps to reduce the unit production cost. Collusion implies higher profits in the product market, because of higher final prices. Firms may thus be prone to increase wages in a collusion setting, since they have a larger return on investment (qualified workers). Indeed, the marginal value (in terms of product) is higher under collusion, which pushes up strategic wages.

Proposition 3: Collusion on the product market leads to higher wages in the qualified labour market.

Corollary 1. Collusion on the product market leads to an increase in productivity, via the recruitment of qualified workers.

Proof. See Annex D. We also provide necessary conditions on parameters to obtain comparable interior solutions.

The classic effect of collusion is price rise and production decrease. But productivity also matters in this model. Collusion decreases production and also causes firms to hire more qualified workers in order to benefit from the resulting increased margin. This strategy allows them to raise productivity and reduce costs. In this way, firms not only charge higher prices, but also have decreased unit production costs, thus raising their final margin.

Despite expectations of a positive correlation between competition and productive performance ${ }^{12}$, we find a negative link. Such a result is in line with the theoretical work of Freshman and Gandalf (1994), who show that collusion on prices can increase the firms' incentives to carry out cost-reducing investments when prices are not the only relevant strategies adopted by firms. Besides, following Schumpeter (1962), it has been argued that less competition implies more R\&D expenditure since firms face less market uncertainty, resulting in a larger and more stable cash flow for firms.

In our model, the first effect of collusion is to raise the wages of the qualified employees, and consequently increase the productivity of the firm. This could generate a potential conflict in a normative analysis of collusion because enhanced productivity represents a benefit that is opposed to inefficiency in the product market. Concerning the total employment level, we need to consider the qualified and unqualified components of the labour market. The opposite effects resulting from collusion are, firstly, to increase the number of qualified workers and secondly, to reduce the number of nonqualified workers, since production decreases. The total effect on employment is therefore ambiguous.

Proposition 4: Collusion on the product market leads to a decrease of total employment level.

12 See Nickell (1999) in section IV. 
Proof. See Annex E.

Collusion on the product market leads to a drop in the quantities produced, but unit productivity increases because the firm hires more qualified workers. Therefore, firms need fewer unqualified workers to produce less quantities since they have higher numbers of qualified workers and each worker is more efficient. ${ }^{13}$ Hence, the total employment level decreases.

A second effect revealed by the normative analysis of collusion is a reduction in total employment, which is clearly not a benefit. Moreover, for many governments, total employment level (rather than qualified employment alone) is the relevant statistic.

It has been currently established that there may be two conflicting effects on the wage bill when total employment level decreases. With falling levels of employment, the wage bill may nevertheless increase due to an increase of competition on the qualified labour market. This last effect may thus be larger when the product market size increases, and thus collusion on the product could lead to a higher wage bill.

\subsection{A numerical illustration of wage bill variation}

Due to the complex analytical expressions of wages and productivity, there is no clear conclusion on how the total wage bill paid by firms varies according to collusion. The argument stated above describes two conflicting effects, but the result remains ambiguous. To obtain a deeper insight on how the model parameters affect the wage bill, we propose two graphical representations according to the set of parameters for the product market $(\alpha, \beta)$ and the (qualified) labour market $(h, t)$. We set $h=\frac{1}{10}$ and $t=\frac{4}{5}$ to illustrate the wage bill variation according to the product market parameters, and use $\alpha=15$ and $\beta=\frac{7}{10}$ to characterise the wage bill with respect to the labour market parameters.

By fixing such parameters, we can compute symmetric equilibrium wages and then derive quantities as well as prices, and thus the number of qualified and unqualified workers. Figure 3 shows the wage bill variation whether there is collusion or not - as a function of product market parameters, while Fig. 4 is relative to labour market parameters. ${ }^{14}$

13 Note that the production function of firm $i$ is given by: $l_{i}+s_{i}=c_{i} q_{i}$. Consequently, if $q_{i}$ decreases and $c_{i}$ increases, the total effect is ambiguous. However, we can demonstrate that the decrease in quantities is more marked than the efficiency gain with collusion. Therefore, because $c_{i} q_{i}$ decreases in collusion and $l_{i}$ increases, we can conclude that $s_{i}$ is lower.

14 Relevant constraints to obtain interior solutions for symmetric wages are indicated as bold lines on both figures. 


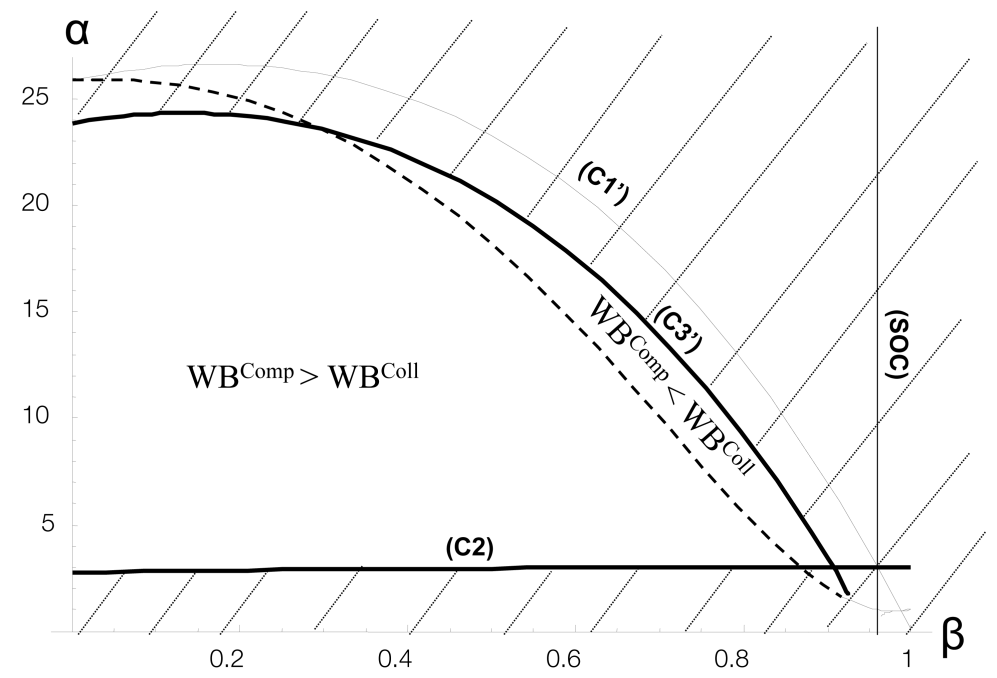

Figure 3: Wage bill on the product market with $h=\frac{1}{10}$ and $t=\frac{4}{5}$

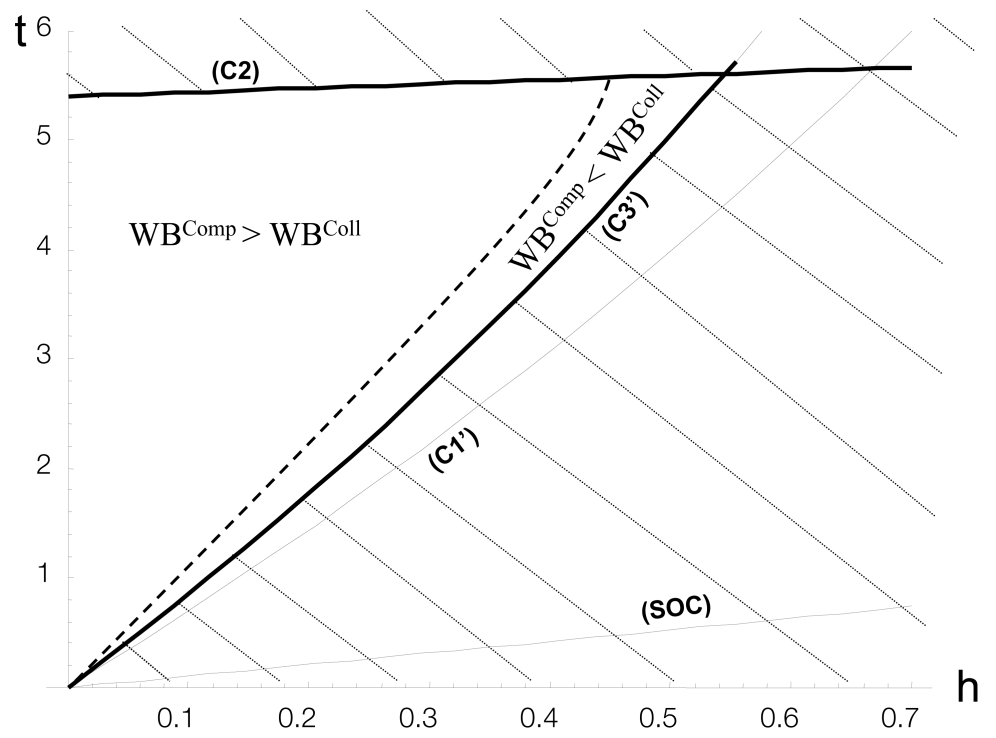

Figure 4: Wage bill on the labour market with $\alpha=15$ and $\beta=\frac{7}{10}$ 
For a given $\alpha$, when substitutability between products is low, the wage bill paid by each firm under competition is higher than the wage bill paid under a collusion agreement on the product market. We can give the following explanation. On the one hand, when products are differentiated, this means that each firm has some market power on its good and thus production is lower, irrespective of whether there is any collusion. In other words, the wage bill increases with the parameter $\beta$ in both frameworks. On the other hand, collusion increases the wage bill because the qualified workers receive higher wages. However, with decreasing substitution of products, this latter effect is weaker because collusion on the product market has a lower impact due to the higher differentiation between final goods. For a given threshold, the effect of collusion via qualified workers compensates the effect of substitutability via the quantities produced.

With respect to labour market parameters, namely the training cost $t$ and the size of labour market $h$, numerical simulations show that the threshold varies in the following way. For a given size of the labour market, when the training cost $t$ increases, there is less competition resulting in lower wages for qualified workers. A weaker competition on the qualified labour market softens the impact of collusion on the product market. This effect becomes more and more important with increasing $t$. Hence, collusion on the product market is less pronounced, leading to a lower wage bill compared to the competition case. For a given training cost $t$, any increase in the labour market size translates into more competition on the qualified labour market. The collusion impact is reinforced by this effect, and increasingly so with higher values of $h$.

The two important results of this analysis are that total employment may decrease because of collusion, and the total wages paid to workers can increase. However, even if the total wage bill increases, inequalities among workers are stronger because of the wider gap between the wages of qualified and non-qualified workers (or unemployed). Therefore, the normative analysis may depend on the social criteria used, and more precisely on whether the gap between qualified and non-qualified workers is taken into account.

\section{Conclusion}

The present article investigates the relation between labour and product markets, taking into account imperfect competition in both markets. The labour market is divided in qualified and unqualified market, which results in an endogenous productivity for firms. The first result of our study is that collusion in the product market leads to higher wages in the qualified labour market. This result is obtained without considering any union for negotiating 
wages, because our model assumes wages are determined in a competitive game. Collusive practices on the product market lead to a decrease in total employment. Nevertheless, the number of qualified workers rises, implying an increase of the firms' productivity. As total employment decreases because of collusion, we should expect a decrease in the wage bill paid by firms. However, when products are close substitutes or when the market size is large enough, there is an increase in the total wage bill paid to workers. This arises from competition on the labour market for qualified workers, leading to higher qualified wages while unqualified wages remain constant. Hence, collusion creates more inequality among workers.

This study draws attention to the interaction between product and labour markets. Although economists are not accustomed to thinking in these terms, our article leads to some possible implications of competition policy that can affect workers. ${ }^{15}$ By modifying the level of competition on the product market, antitrust authorities may influence the firms' requirements for skilled and unskilled workers, and therefore the labour market structure. Productivity performances are also changed.

Our work could be extended to deal with technology spill-overs and the location of firms. In our model, the same firms are present both on the labour and product markets. This implicitly assumes that the product market is made up of non-traded goods. By contrast, assuming that the product market is larger, considering different locations for the labour market would therefore change the product market competition. Product market competition does indeed depend on the labour markets where firms hire. Therefore, considering the firms' location, the benefits of spatial clustering in the same labour market could then be different according to whether there is product market competition or collusion.

\section{Bibliography}

Beffy M., M. Buchinsky, D. Fougère, T. Kamionka and F. Kramartz (2006). "The Returns to Seniority in France (and Why they are Lower than in the United States)", IZA Discussion Paper \# 1935.

Bhaskar V., A. Manning and T. To (2002). "Oligopsony and Monopsonistic Competition in Labor Market", Journal of Economic Perspectives, 16(2), pp.155-174.

Blanchflower D.G., A.J. Oswald and P. Sanfey (1996). "Wages, Profits, and Rent-Sharing", Quarterly Journal of Economics, 111(1), pp.227-251.

15 See Perrot (2002) for an introduction to this point of view. 
Cahuc P., F. Postel-Vinay and J.-M. Robin (2006). "Wage Bargaining with Onthe-job Search: Theory and Evidence", Econometrica, 74(2), pp.323-364.

Combes P-P. and G. Duranton (2006). "Labour pooling, Labour poaching and Spatial clustering", Regional Science and Urban Economics, 36, pp.1-28.

Davidson C. (1988). "Multiunit Bargaining in Oligopolistic Industries", Journal of Labor Economics, 6(3), pp.397-422.

Fershtman C. and N. Gandal (1994). "Disadvantageous semicollusion", International Journal of Industrial Organization, 12, pp.141-154.

Fosfuri A., M. Motta and T. Rønde (2001). "Foreign direct investment and spillovers through workers' mobility", Journal of International Economics, 53, pp. 205-222.

Fosfuri A. and T. Rønde (2004). "High-tech clusters, technology spillovers, and trade secret laws", International Journal of Industrial Organization, 22, pp.45-65.

Gersbach H. and A. Schmutzler (2003). "Endogenous spillovers and incentives to innovate", Economic Theory, 21, pp.59-79.

Hamilton J., J.-F. Thisse and Y. Zenou (2000). "Wage competition with heterogeneus workers and firms", Journal of Labor Economics, 18(3), pp.453-472.

Horn H., H. Lang and S. Lundgren (1994). "Competition, long-run contracts and internal inefficiencies in firms", European Economic Review, 38, pp.213-234.

Horn H. and A. Wolinski (1988). "Bilateral Monopolies and Incentives for Merger", Rand Journal of Economics, 19(3), pp.408-419.

Irmen A. (1997). "Note on duopolistic vertical restraints", European Economic Review, 41, pp.1559-1567.

Lommerud K. E., Straume O. R. and L. Sørgard (2005). "Downstream merger with upstream market power", European Economic Review, 49, pp.717-743.

Lommerud K. E., Straume O. R. and L. Sørgard (2006). "National versus international mergers in unionised oligopoly", Rand Journal of Economics, 37(1), pp.212-233.

Manning A. (2003). "The real thin theory: monopsony in labour markets", Labour Economics, 10, pp.105-131.

Mills D. and Smith W. (1996). "It pays to be different: endogenous heterogeinity of firms in an oligopoly", International Journal of Industrial Organization, 14, pp.317-329.

Naylor R. (2003). "Economic Models of Union Behaviour", in: Addison J.T. and C. Schnabel (eds), International Handbook of Trade Unions, Edward Elgar, chapter 2. 
Nickell S. (1999). "Product markets and labour markets", Labour Economics, 6 , pp.1-20.

Perrot A. (2002). "Les frontières entre régulation sectorielle et politique de la concurrence", Revue française d'économie, XVI(4), pp.81-110.

Sattinger M. (1993). "Assignment Models of the Distribution of Earnings", Journal of Economic Litterature, 31, pp.831-880.

Schumpeter J.A. (1962). Capitalism, Socialism and Democracy, New York: Harper Torchbooks.

Stewart M. (1990). "Union Wage Differentials, Product Market Influences and the Division of Rents", The Economic Journal, 100, pp.11221137.

Symeonidis G. (2005). "Collusion, Bargaining and Welfare", Mimeo University of Essex.

Vives X. (1989). "Technological competition, uncertainty and oligopoly", Journal of Economic Theory, 48, pp.386-415.

Wauthy X. and Y. Zenou (2000). "How the adoption of a new technology is affected by the interaction between labor and product markets?", in: Norman G. and J-F. Thisse (eds), Market Structures and Competition Policy: Game Theory approaches, Cambridge University Press, pp. 271-286.

\section{Annexes}

\section{A Qualified labour market supply relative to wages}

The labour market is horizontally differentiated across qualified workers' skills. Workers are uniformly distributed along the segment $\left[-\frac{1}{h}, \frac{1}{h}\right]$ and firms are located at $x_{2}=-\frac{1}{2}$ and $x_{1}=\frac{1}{2}$. The situation on the qualified market is illustrated on Figure 2 in the main text.

The worker indifferent between being hired by firm 1 or firm 2 satisfies the condition:

$$
w_{1}-t\left(\tilde{x}+\frac{1}{2}\right)=w_{2}-t\left(\frac{1}{2}-\tilde{x}\right) \Leftrightarrow \tilde{x}=\frac{w_{1}-w_{2}}{2 t} .
$$

The worker indifferent between working for firm 1 or not working satisfies the condition:

$$
w_{1}-t\left(-\frac{1}{2}-x_{1}^{*}\right)=0 \Leftrightarrow x_{1}^{*}=-\left(\frac{w_{1}}{t}+\frac{1}{2}\right) .
$$


The worker indifferent between working for firm 2 or not working satisfies the condition:

$$
w_{2}-t\left(x_{2}^{*}-\frac{1}{2}\right)=0 \Leftrightarrow x_{2}^{*}=\frac{w_{2}}{t}+\frac{1}{2} .
$$

Given wages $w_{1}$ and $w_{2}$ and a uniform density $h$, the number of qualified workers hired by each firm at such wages can be obtained as follows:

$l_{1}\left(w_{1}, w_{2}\right)=h\left(\tilde{x}-x_{1}^{*}\right)=h \frac{3 w_{1}-w_{2}+t}{2 t}$ and $l_{2}\left(w_{1}, w_{2}\right)=h\left(x_{2}^{*}-\tilde{x}\right)=h \frac{3 w_{2}-w_{1}+t}{2 t}$.

In order to remain in the case where the qualified market is not fully covered, it is necessary to satisfy the condition $\left|x_{i}\right|<\frac{1}{h}$. This is expressed by $w_{i}<t\left(\frac{1}{h}-\frac{1}{2}\right)$. Besides, for the firms to be effectively competing for qualified workers, the worker with a skill $\tilde{x}$ must have a positive utility. It follows that $w_{1}-t\left(\frac{1}{2}+\tilde{x}\right)>0$, but since $\tilde{x}=\frac{w_{1}-w_{2}}{2 t}$, the wages must satisfy $w_{1}+w_{2}>t$. Moreover, the previous conditions imply that $h<1$ is a prerequisite for competition on the qualified labour market in the case where the labour market is not fully covered.

\section{B Wage equilibrium with competition on the product market}

The first-order condition (FOC) with respect to $w_{i}$ is given in equation (14). We only consider symmetric wage equilibria where $w_{i}=w_{j}=w$, hence it follows that the $\mathrm{FOC}$ is given by:

$$
\left(\frac{h(2 w+t)}{2 t}+\alpha-1\right) A-(5 w+t)=0 \text { where } A=\frac{12+2 \beta-6 \beta^{2}}{(1+\beta)(2+\beta)(2-\beta)^{2}}>0 \text {. }
$$

We can then write:

$$
w^{*}=\frac{t^{2}-A\left(\alpha-1+\frac{h}{2}\right) t}{h A-5 t} .
$$

The asymptotic stability of the symmetric Nash-equilibrium is fulfilled as long as the second-order conditions (SOC) are satisfied:

$$
\frac{\partial^{2} \pi_{i}\left(w_{i}, w_{j}\right)}{\partial w_{i}^{2}}<0(S O C 1) \text { and } \frac{\partial^{2} \pi_{i}\left(w_{i}, w_{j}\right)}{\partial w_{i}^{2}} \cdot \frac{\partial^{2} \pi_{i}\left(w_{i}, w_{j}\right)}{\partial w_{j}^{2}}-\frac{\partial^{2} \pi_{i}\left(w_{i}, w_{j}\right)}{\partial w_{i} \partial w_{j}} \cdot \frac{\partial^{2} \pi_{i}\left(w_{i}, w_{j}\right)}{\partial w_{j} \partial w_{i}}>0 \text { (SOC2). }
$$

This is true when:

$$
t>\frac{h\left(3 \beta^{2}-6-\beta\right)^{2}}{6\left(4-\beta^{2}\right)^{2}\left(1-\beta^{2}\right)}(S O C 1)
$$

and 


$$
t>\frac{h\left(6+\beta-3 \beta^{2}\right)\left(8+4 \beta-4 \beta^{2}\right)}{7\left(4-\beta^{2}\right)^{2}\left(1-\beta^{2}\right)} \text { and } t<\frac{2 h\left(6+\beta-3 \beta^{2}\right)\left(2-\beta-\beta^{2}\right)}{5\left(4-\beta^{2}\right)^{2}\left(1-\beta^{2}\right)}
$$

Since $0<\beta<1$, these three conditions amount to:

$$
t>\frac{h\left(6+\beta-3 \beta^{2}\right)\left(8+4 \beta-4 \beta^{2}\right)}{7\left(4-\beta^{2}\right)^{2}\left(1-\beta^{2}\right)} \quad(\mathrm{SOC}) .
$$

To compute comparative statics, we apply the implicit function theorem to the first-order condition:

$$
\frac{d w^{*}}{d y}=-\frac{\frac{\partial F O C}{\partial y}}{\frac{\partial F O C}{\partial w}} \text { with } \frac{\partial F O C}{\partial w}<0 \quad(\mathrm{SOC} 1) .
$$

This leads to:

$$
\begin{aligned}
& \frac{d w^{*}}{d \alpha}>0, \text { since } \frac{\partial F O C}{\partial \alpha}=A>0 \text { with } \beta \in[0,1[; \\
& \frac{d w^{*}}{d \beta}<0 \text {, because } \\
& \quad \frac{\partial F O C}{\partial \beta}=\underbrace{\left.\frac{h\left(2 w^{*}+t\right)}{2 t}+\alpha-1\right)}_{>0} \underbrace{\frac{\partial A}{\partial B}<0 \quad \text { with } \beta \in[0,1[;}_{<0}
\end{aligned}
$$

$\frac{d w^{*}}{d h}>0$, since $\frac{\partial F O C}{\partial h}=\frac{\left(2 w^{*}+t\right)}{2 t} A>0$ with $\beta \in\left[0,1\left[;\right.\right.$ and $\frac{d w^{*}}{d t}<0$ because $\frac{\partial F O C}{\partial t}=\frac{h w^{*}}{t^{2}} A-1<0$ with $\beta \in[0,1[$.

For the labour market to be globally elastic (and thus not completely covered), the number of qualified workers hired by each firm should be such that: $l_{i}\left(w^{*}\right)<1$. This condition is equivalent to:

$$
t>\frac{2 h \alpha A}{(10-3 h)}(\mathrm{C} 1) \text {. }
$$

Besides, we need to maintain $w^{*}>\frac{t}{2}$ to have effective competition on the labour market. Applying this condition at the equilibrium with the FOC, we obtain:

$$
t<\frac{2(h+\alpha-1) A}{7}
$$

Lastly, we can rewrite the condition that the number of unqualified workers hired in the second stage must be positive $\left(s^{*}>0 \Leftrightarrow l^{*}<c^{*} q^{*}\right)$ :

$$
t>\frac{A h[(2+\beta(1-\beta))(3 h+10(1-\alpha))+(\alpha+B)(-3 h+10(1-\alpha))]}{9 h^{2}+100(1-\alpha)+30 h(\alpha+\beta(1-\beta))}(\mathrm{C} 3) \text {, }
$$

with $B=\sqrt{\alpha^{2}+4(\alpha-1)+\beta(1-\beta)(2 \alpha+\beta(1-\beta))}$. 
Note that, since $0 \leq h<1$, there always exists a non-empty set of values of $t$ defined by conditions (C1), (C2) and (C3).

\section{Wage equilibrium with collusion on the product market}

The first-order condition (FOC) with respect to $w_{i}$ is given in equation (20). We consider a symmetric wage equilibrium where $w_{i}=w_{j}=w$ leading to the FOC:

$$
\left(\frac{h(2 w+t)}{2 t}+\alpha-1\right) C-(5 w+t)=0 \text { where } C=\frac{3-\beta}{2(1-\beta)(1+\beta)}>0 .
$$

This leads directly to an equilibrium wage with collusion on the product market, which can be written as:

$$
w^{* *}=\frac{t^{2}-C\left(\alpha-1+\frac{h}{2}\right) t}{h C-5 t} .
$$

The asymptotic stability of the symmetric Nash-equilibrium is fulfilled as long as $\frac{\partial^{2} \pi_{i}\left(w_{i} w_{j}\right)}{\partial w_{i}^{2}}<0$ (SOC1') and $\frac{\partial^{2} \pi_{i}\left(w_{i}, w_{j}\right)}{\partial w_{i}^{2}} \cdot \frac{\partial^{2} \pi_{i}\left(w_{i}, w_{j}\right)}{\partial w_{j}^{2}}-\frac{\partial^{2} \pi_{i}\left(w_{i} w_{j}\right)}{\partial w_{i} \partial w_{j}} \cdot \frac{\partial^{2} \pi_{i}\left(w_{i}, w_{j}\right)}{\partial w_{j} \partial w_{i}}>0$ (SOC2').

This is true when:

$$
t>\frac{h(3+\beta)}{8\left(1-\beta^{2}\right)}\left(\mathrm{SOC}^{\prime}\right)
$$

Condition (SOC2') can be re-expressed as:

$$
\begin{gathered}
t>\frac{8 h\left(9+3 \beta-2 \beta^{2}\right)}{4\left(1-\beta^{2}\right)\left(51-13 \beta+\sqrt{81-2166 \beta+729 \beta^{2}}\right)} \\
\text { or } t<\frac{8 h\left(9+3 \beta-2 \beta^{2}\right)}{4\left(1-\beta^{2}\right)\left(51-13 \beta-\sqrt{81-2166 \beta+729 \beta^{2}}\right)}\left(\text { SOC } 2^{\prime}\right) .
\end{gathered}
$$

Since $0<\beta<1$, these three conditions amount to:

$$
t>\operatorname{Max}\left\{\frac{h(3+\beta)}{8\left(1-\beta^{2}\right)}, \frac{8 h\left(9+3 \beta-2 \beta^{2}\right)}{4\left(1-\beta^{2}\right)\left(51-13 \beta+\sqrt{81-2166 \beta+729 \beta^{2}}\right)}\right\} \text { (SOC'). }
$$

For computing comparative statics, we apply the implicit function theorem to the first-order condition: 


$$
\frac{d w^{* *}}{d y}=-\frac{\frac{\partial F O C}{\partial y}}{\frac{\partial F O C}{\partial w}} \text { with } \frac{\partial F O C}{\partial w}<0\left(\mathrm{SOC}^{\prime}\right)
$$

This leads to:

$\frac{d w^{* *}}{d \alpha}>0$, because $\frac{\partial F O C}{\partial \alpha}=C>0$ with $\beta \in\left[0,1\left[; \frac{d w^{* *}}{d \beta}<0\right.\right.$ when $\beta \in[0,3-2 \sqrt{2}[$, and $\frac{d w^{* *}}{d \beta} \geq 0$ otherwise since

$$
\frac{\partial F O C}{\partial \beta}=\left(\frac{\frac{h\left(2 w^{* *}+t\right)}{2 t}+\alpha-1}{\underbrace{*}}\right) \frac{\partial C}{\partial \beta} ;
$$

$\frac{d w^{* *}}{d h}>0$, because $\frac{\partial F O C}{\partial h}=\frac{\left(2 w^{* *}+t\right)}{2 t} C>0$ with $\beta \in\left[0,1\left[\right.\right.$; and $\frac{d w^{* *}}{d t}<0$, since $\frac{\partial F O C}{\partial t}=-\frac{h w^{* *}}{t^{2}} C-1<0$ with $\beta \in[0,1[$.

For the labour market to be globally elastic (and thus not completely covered), the number of qualified workers hired by each firm should be such that $l_{i}\left(w^{* *}\right)<1$. This condition is equivalent to:

$$
t>\frac{2 h \alpha C}{(10-3 h)}\left(\mathrm{C} 1^{\prime}\right)
$$

Besides, to have effective competition on the labour market, we need to assume $w^{* *}>\frac{t}{2}$. Applying this condition at the equilibrium with the FOC, we obtain:

$$
t<\frac{2(h+\alpha-1) C}{7}\left(\mathrm{C} 2^{\prime}\right)
$$

Lastly, if the number of unqualified workers hired in the second stage is positive $\left(s^{* *}>0 \Leftrightarrow l^{* *}<c^{* *} q^{* *}\right)$, we can rewrite the condition as follows:

$$
\begin{gathered}
t>\frac{C h[2(1+\beta)(3 h+10(1-\alpha))+(\alpha+D)(-3 h+10(1-\alpha))]}{9 h^{2}+100(1-\alpha)+30 h(\alpha+2 \beta)}\left(\mathrm{C}^{\prime}\right), \\
\text { with } D=\sqrt{\alpha^{2}+4(\alpha-1)+4 \beta(\alpha+\beta)} .
\end{gathered}
$$

Note that, as in the competition case, since $0 \leq h<1$, there always exists a non-empty set of values of $t$ defined by conditions (C1'), (C2') and (C3'). 


\section{The effect of collusion on wages}

In each symmetric equilibrium defined on wages, particular conditions apply for interior solutions, profit maximisation and stability. When comparing wages between the two frameworks, we first need to define which conditions are the more stringent. It is straightforward to show that $\left(C 1^{\prime}\right)$ is more binding than (C1), so $t>\frac{2 \alpha h C}{10-3 h}\left(C 1^{\prime}\right)$. (C2) is more binding than (C2'), and hence $t<\frac{2(h+\alpha-1) A}{7}(C 2)$. Likewise, (C3') is more binding than (C3), and thus:

$$
t>\frac{C h[2(1+\beta)(3 h+10(1-\alpha))+(\alpha+D)(-3 h+10(1-\alpha))]}{9 h^{2}+100(1-\alpha)+30 h(\alpha+2 \beta)}\left(\mathrm{C}^{\prime}\right) .
$$

Finally, the comparisons between (SOC) and (SOC') lead to $t>\frac{h\left(6+\beta-3 \beta^{2}\right)\left(8+4 \beta-4 \beta^{2}\right)}{7\left(4-\beta^{2}\right)^{2}\left(1-\beta^{2}\right)}($ SOC $)$ since $\beta \in[0,1[$.

We now turn to the wages comparison. Let us define:

$$
\phi(y)=\frac{t^{2}-y\left(\alpha-1+\frac{h}{2}\right) t}{h y-5 t}
$$

It follows that:

$$
\frac{d \phi}{d y}=\frac{t^{2}(3 h+10(-1+\alpha))}{2(-5 t+h x)^{2}}>0 \text { because of } \alpha>1
$$

Thus, $\phi$ is strictly increasing. Since $C>A$ for $\beta \in[0,1[$, it follows that:

$$
\phi(C)=w^{* *}>\phi(A)=w^{*} .
$$

\section{E The effect of collusion on employment structure}

We aim to prove that collusion on the product market leads to a decrease of employment level. Our outline proof is the following: since collusion implies a decrease of unit cost, the total employment level decreases (because $c \cdot q=l+s$ ) if collusion on the product market leads to a decrease of the quantity of output $\left(q^{* *}<q^{*}\right)$. In this way, we merely demonstrate that $q^{* *}<q^{*}$.

The number of qualified workers hired by firm $i$ is given by:

$$
l_{i}\left(w_{i}, w_{j}\right)=\frac{\left(3 w_{i}-w_{j}+t\right)}{2 t} h \text { with } i \neq j=\{1,2\} .
$$

At the symmetric equilibrium in wages, this expression becomes: 


$$
l(w)=\frac{(2 w+t)}{2 t} h .
$$

The symmetric equilibrium wage can then be rewritten as follows:

$$
w=-\frac{t}{2}+\frac{t}{h} l=-\frac{t}{2}+\frac{t}{h}(1-c) \text { because } l=1-c .
$$

When there is collusion on the product market, the first-order condition on the labour market is:

$$
\left(\frac{h(2 w+t)}{2 t}+\alpha-1\right) \frac{(3-\beta)}{2(1-\beta)(1+\beta)}-(5 w+t)=0 .
$$

Using the previous expression of the symmetric equilibrium wage and the number of qualified workers, we can rewrite the first-order condition as follows:

$$
\left(-c^{* *}(q)+\alpha\right) \frac{(3-\beta)}{2(1-\beta)(1+\beta)}-\left[5\left(-\frac{t}{2}+\frac{t}{h}\left(1-c^{* *}(q)\right)\right)+t\right]=0,
$$

where $c^{* *}(q)$ is the unit cost at equilibrium. In the collusion framework, the quantities chosen by firm $i$ are such that:

$$
q_{i}\left(c_{i}, c_{j}\right)=\frac{\alpha}{2(1+\beta)}+\frac{\beta c_{j}-c_{i}}{2(1+\beta)(1-\beta)} .
$$

But since $c_{i}=c_{j}=c^{* *}$ at the symmetric equilibrium, it follows that:

$$
c^{* *}\left(q^{* *}\right)=\alpha-2(1+\beta) q^{* *} .
$$

The expression of $c^{* *}\left(q^{* *}\right)$ with respect to quantities can then be substituted into the first-order condition, thus giving:

$$
\mathrm{FOC}^{\mathrm{Coll}}\left(q^{* *}\right)=\frac{(3-\beta)}{(1-\beta)} q^{* *}-\left[5\left(-\frac{t}{2}+\frac{t}{h}\left(2(1+\beta) q^{* *}-\alpha+1\right)\right)+t\right]=0
$$

We carry out the same operations for the case where there is competition on the product market. The first condition can be written as:

$$
\left(\frac{h(2 w+t)}{2 t}+\alpha-1\right) A-(5 w+t)=0 \text {. }
$$

which leads to:

$$
\left(-c^{*}(q)+\alpha\right) A-\left[5\left(-\frac{t}{2}+\frac{t}{h}\left(1-c^{*}(q)\right)\right)+t\right]=0 .
$$

In the competition framework, the quantities produced by firm $i$ at equilibrium are given by:

$$
q_{i}\left(c_{i}, c_{j}\right)=\frac{\alpha}{(2-\beta)(1+\beta)}+\frac{\beta c_{j}-\left(2-\beta^{2}\right) c_{i}}{(2+\beta)(2-\beta)(1+\beta)(1-\beta)},
$$


leading to:

$$
c^{*}\left(q^{*}\right)=\alpha-(2-\beta)(1+\beta) q^{*} .
$$

The initial first-order condition on wages can then be expressed with respect to quantities:

$$
\mathrm{FOC}^{\mathrm{Comp}}\left(q^{*}\right)=\frac{\left(12+2 \beta-6 \beta^{2}\right)}{(2+\beta)(2-\beta)} q^{*}-\left[5\left(-\frac{t}{2}+\frac{t}{h}\left((2-\beta)(1+\beta) q^{*}-\alpha+1\right)\right)+t\right]=0 .
$$

Therefore, while equation (21) is evaluated in terms of quantities assuming collusion on the product market, the first-order condition in the competition framework (cf. equation (22)) can be reformulated as:

$$
\operatorname{FOC}^{\mathrm{Comp}}\left(q^{* *}\right)=\left[\frac{\left(12+2 \beta-6 \beta^{2}\right)}{(2+\beta)(2-\beta)}-\left(\frac{(3-\beta)}{(1-\beta)}-5 \frac{t}{h} \beta(1+\beta)\right)\right] q^{* *} .
$$

Because $t>\frac{h\left(6+\beta-3 \beta^{2}\right)\left(8+4 \beta-4 \beta^{2}\right)}{7\left(4-\beta^{2}\right)^{2}\left(1-\beta^{2}\right)}($ SOC $)$, as explained in Annex D, this implies $\mathrm{FOC}^{\mathrm{Comp}}\left(q^{* *}\right)>0$. Therefore, owing to the concavity of the objective function, $q^{* *}<q^{*}$.

From Proposition 3, collusion generates an increase in productivity: $c^{* *}\left(q^{* *}\right)<c^{*}\left(q^{*}\right)$. Because $q^{* *}<q^{*}$, we have $c^{* *} q^{* *}=l^{* *}+s^{* *}<c^{*} q^{*}=l^{*}+S^{*}$ and thus collusion results in a lower total employment. 